\title{
MECHANICAL PROPERTIES OF DENTAL RESTORATIVE MATERIALS: RELATIVE CONTRIBUTION OF LABORATORY TESTS
}

\section{PROPRIEDADES MECÂNICAS DOS MATERIAIS DENTÁRIOS RESTAURADORES: CONTRIBUIÇÃO RELATIVA DOS ENSAIOS LABORATORIAIS}

\author{
Linda WANG \\ DDS, MS, PhD student, Department of Operative Dentistry, Endodontics and Dental Materials, Bauru Dental School, University of São \\ Paulo, Bauru, São Paulo, Brazil. \\ Paulo Henrique Perlatti D’ALPINO \\ DDS, MS, PhD student, Department of Operative Dentistry, Endodontics and Dental Materials, Bauru Dental School, University of São \\ Paulo, Bauru, São Paulo, Brazil.

\section{Lawrence Gonzaga LOPES} \\ DDS, MS, PhD student, Department of Operative Dentistry, Endodontics and Dental Materials, Bauru Dental School, University of São \\ Paulo, Bauru, São Paulo, Brazil. \\ José Carlos PEREIRA \\ DDS, MS, PhD Professor, Department of Operative Dentistry, Endodontics and Dental Materials, Bauru Dental School, University of São \\ Paulo, Bauru, São Paulo, Brazil.
}

\begin{abstract}
A wide variety of dental products that are launched on the market becomes the correct selection of these materials a difficult task. Although the mechanical properties do not necessarily represent their actual clinical performance, they are used to guide the effects of changes in their composition or processing on these properties. Also, these tests might help somehow the clinician to choose once comparisons between former formulations and new ones, as well as, with the leading brand, are highlighted by manufactures. This paper presents a review of the most important laboratory tests. In this manner, the knowledge of these tests will provide a critical opinion related to the properties of different dental materials.
\end{abstract}

UNITERMS: Dental materials, properties; Materials testing.

\section{INTRODUCTION}

In the current dental literature, several studies evaluate distinct properties of dental materials, which can influence and predict their performance $e^{1,2,5,6,7,10,19}$. Dental products have been developed very rapidily and, consequently, the number of studies designed to evaluate their characteristics is also increasing. Practitioners are aware of the importance of previous laboratory and clinical trials before putting the material into use in their practice. In this way, the knowledge of their mechanical properties is essential to support the correct indication of these materials and to expect a long-term performance ${ }^{20}$.

Once in the oral cavity, a dynamic situation is established and then, adverse conditions to the material can be expected ${ }^{8,13,17,20}$. For different situations, each material would respond in a particular way. Several in vitro tests are proposed to evaluate different properties. Each test has its design and evaluates specific properties. Although there is a great number of studies that evaluate dental materials in the literature, in some cases it is somewhat difficult to compare the results. In order to seek for standardized testing protocols, an international organization was created to act in that direction. Table 1 presents the main guidance for dental materials laboratory testing recommended by International Organization for Standardization (ISO). A review of the usual tests that evaluate mechanical properties of dental materials is presented in an attempt to demonstrate their applicability and relevance. 


\section{MECHANICAL PROPERTIES}

In the oral environment, restorations are subjected to stresses from mastication action. These forces act on teeth and/ or material producing different reactions that lead to deformation, which can ultimately compromise their durability over time ${ }^{1,8,9,17,18}$. It is important to introduce some concepts that are extremely relevant to understand the performance presented by such material under specific test conditions. This information will be useful to analyze possible reaction of such restorative dental material when clinically in service.

When a specific force or load is applied to a body, a reaction of the same intensity and with opposite direction is produced. It results in an internal tension. In a simple way of interpretation, it is possible to quantify the reaction resulted by the applied external load. Since shape and dimensions of specimens under test can be measured, one can calculate stress by the reason between force and unit area.

Depending on the applied load characteristics and consequent stress, different reactions from the tested material may occur. The stress can result in structural alteration of original dimensions. The rate between this alteration by the original dimension results in deformation, that is defined as strain. Although a more complex process develops, it is stated that the body reacts uniformly in any layer of it. This is defined as principle of uniformity ${ }^{4}$.

The stress-strain ratio of a material is relevant to determine its mechanical behavior. For each material, there is a stress-strain proportional relationship, establishing a stress-strain curve. If there is a stress relief during loading and no permanent deformation occurs, it demonstrated its elasticity. This proportion occurs until a limit point that is defined as proportional limit and deformation as elastic deformation (Figure 1). In this point, the maximum stress of a material will withstand without permanent deformation. As stress-strain is proportional until this point, there is a constant proportionality. It determines the elasticity of a material and is calculated by the ratio of stress-strain curve within the elastic limit. This proportionality is defined as modulus of elasticity or Young's modulus (Figure 2). This value will measure the stiffness of such material. However, when the applied load exceeds this point, irreversible deformation occurs, resulting in permanent or plastic deformation. Each material presents a resistance to deformation, and after this point, it will result in its rupture. In this point ultimate strength value is obtained.

Other concepts can be explored by the stress-strain curve of a material. The area under the elastic portion of the stress-strain curve represents the resilience of the material (Figure 3). It corresponds to resistance of a material to permanent deformation and indicates the amount of energy required to deform the material to its proportional limit. When the area under the elastic and plastic portions of a stress-strain curve is calculated, it indicates the toughness of a material. Toughness is the resistance of a material to fracture and correspond to the amount of energy required to cause it.

All these concepts can be applied in clinical situations. Since many complex forces occur and tend to deform the material (tensile, compressive, shear, bending forces), the knowledge and interpretation of how these materials behave under such forces are relevant to understand the performance of the material.

\section{TENSILE STRENGTH}

When a body is subjected to axial forces in a straight line and in opposite directions, it results in tension. The

TABLE 1- ISO specifications to guide dental tests

1559:1995

1564:1995

1942-2:1989

6876:2001

7405:1997

7491:2000

9333:1990

10271:2001

11245:1999

TS $11405: 2003$

TS 14569-1:1999

TS 14569-2:2001
Dental materials - Alloys for dental amalgam

Dental aqueous impression materials based on agar

Dental vocabulary - Part 2: Dental materials

Dental root canal sealing materials

Dentistry - Preclinical evaluation of biocompatibility of medical devices used in dentistry -

Test methods for dental materials

Dental materials — Determination of colour stability

Dentistry -Brazing materials

Dental metallic materials - Corrosion test methods

Dental restorations - Phosphate-bonded refractory die materials

Dental materials - Testing of adhesion to tooth structure (available in English only)

Dental materials - Guidance on testing of wear - Part 1: Wear by toothbrushing

Dental materials - Guidance on testing of wear - Part 2: Wear by two- and/or three body contact 
resistance of the material to this load is called tensile strength $^{4,8}$. The length alteration that results from the application of a tensile force on a body before its rupture is defined as elongation. Nominal value of tensile strength is determined by the equation of load and cross-sectional area $\left(\mathrm{Kgf} / \mathrm{cm}^{2}\right)$. Values of stress-strain determine a curve, characterizing the performance of the material under tensile test. From this curve, elastic modulus, ultimate tensile strength, resilience and toughness of such product can be registered.

In this test, it is common to measure the ductibility of a material. It is an important feature of metallic materials because it is the ability of the material to deform under tensile forces until the fracture moment and indicates the workability of an alloy.

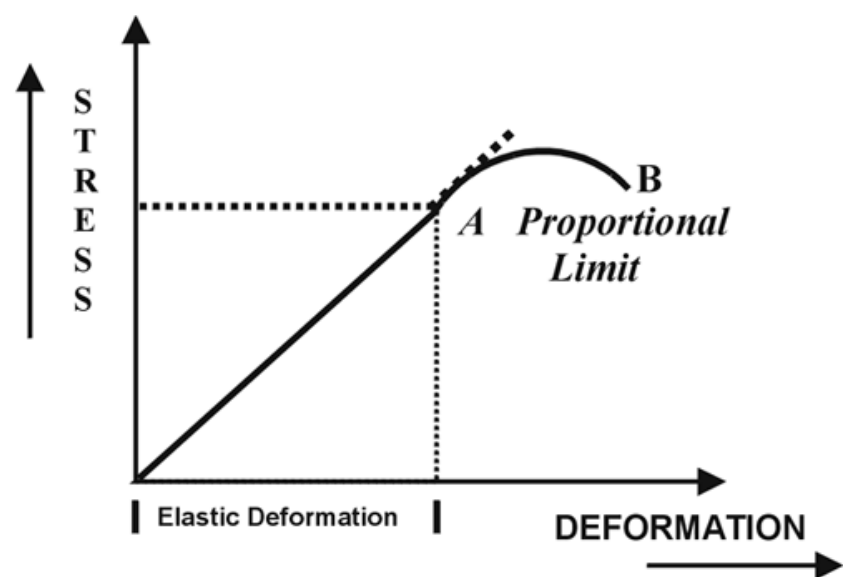

FIGURE 1- Stress-strain curve for hypothetical material: Proportional limit $(A)$, elastic deformation (point $A$ ) and plastic deformation (between points $A$ e $B$ ). Point $B$ represents the moment of rupture of the material under tensile condition.

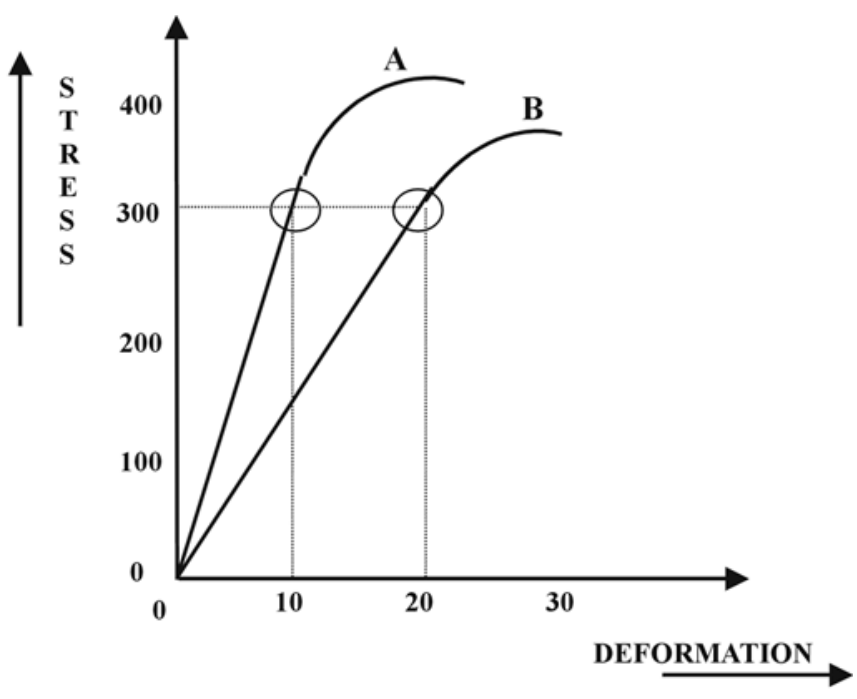

FIGURE 2- Stress-strain curve for hypothetical materials (A e B) showing that $A(30 \mathrm{GPa})$ presents higher elastic modulus than $B(15 \mathrm{GPa})$

\section{DIAMETRAL COMPRESSION TEST}

Rupture under low tension characterizes fragile materials, susceptible to brittle. In these cases, tensile strength is not indicated to evaluate material reaction, because of the low cohesive condition. An alternative method of tensile strength is calculated by compressive testing. It is a relative simple and reproducible test. It is defined as diametral compression test for tension or indirect tension ${ }^{3,4,6,7,8}$. Disk sample is necessary to conduct this test, where it is compressed diametrically introducing tensile stress in the material in the plane of the force application by the test (Figure 4). This is calculate by the formula:

$$
\begin{aligned}
& 2 \mathrm{P} / \pi \times \mathrm{D} \times \mathrm{T}, \\
& \text { where: } \\
& \mathrm{P}=\text { load applied, } \\
& \mathrm{D}=\text { diameter of the disk, } \\
& \mathrm{T}=\text { thickness of the disk, } \\
& \pi=\text { constant }
\end{aligned}
$$

\section{COMPRESSIVE STRENGHT}

Since most of mastication forces are compressive in nature, it is important to investigate materials under this condition $^{8}$. This test is more suitable to compare brittle materials, which show relatively low result when subject to tension. Therefore, this test is applied to compare dental amalgam, impression materials, investments and cements. Materials that are more resistant under compressive forces than under tensile forces, are called malleable.

To test compressive strength of a material, two axial sets of force are applied to a sample in an opposite direction, in order to approximate the molecular structure of the material. According to ISO $9917^{11}$, cylindricalshaped specimens are tested. The dimensions of the samples should have a relation of length to diameter of $2: 1$. When this proportion is exceeded, it can result in undesirable bending of the specimen ${ }^{8}$.

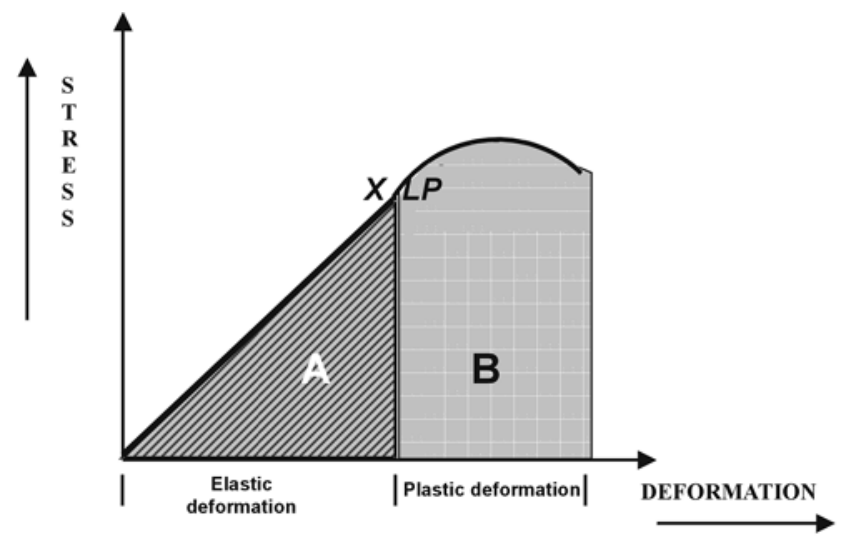

FIGURE 3- Areas indicating resilience $(A)$ and toughness $(A+B)$ of a material 
In the same manner of tensile strength, nominal value of compressive strength also is determined by the reason of load by cross-sectional area $\left(\mathrm{Kgf} / \mathrm{cm}^{2}\right)$.

Stress-strain curve of investigated material is determined as the same manner as established to tensile tests. Thus, the elastic modulus can also be determined by the ratio stress-strain in the elastic region.

\section{POISSON RATIO}

When a material is under axial loading as tensile or compression tests, it is stated that the stress provokes strain in an axial direction. However, lateral strain also occurs $^{4,8}$. Then, tensile force results in material elongation in the axial direction and a reduction of the cross-section. On the other hand, compressive force leads material to increase in the cross-section and reduction of original length. If these reactions occur in the elastic limit, the ratio between lateral and axial strain is denominated Poisson's ratio. Poisson's ratio indicates that the alteration in cross-section is proportional to the deformation during the elastic range. Brittle materials show little permanent reduction in cross-section during tensile test situations than more ductile materials.

\section{FLEXURAL STRENGTH}

The flexural strength of a material is its ability to bend before it breaks. ${ }^{2,3}$ It is obtained when the ultimate flexibility of one material is achieved before its proportional limit ${ }^{3}$. Flexural forces are the result of forces generated in clinical situations and the dental materials need to withstand repeated flexing, bending, and twisting. A high flexural strength is desired once these materials are under the action of chewing stress that might induce permanent deformation.

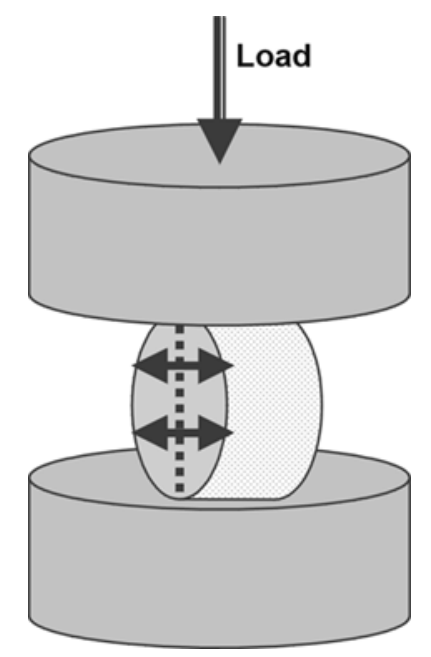

FIGURE 4- Schematic illustration of diametral compression test
To evaluate flexural strength of a dental material, it is generally used bar-shaped specimens with dimension of $25 \mathrm{~mm}$ in length X $2 \mathrm{~mm}$ in width X $2 \mathrm{~mm}$ in height (ISO $9917-2^{12}$ ). Specimens are placed on two supports and a load is applied at the center. This test is known as three-point bending test (Figure 5). The load at yield is the sample material's flexural strength that is calculated by the following formula:

$$
\begin{aligned}
& \frac{3 \mathrm{Pl}}{2 \mathrm{bd} \mathrm{d}^{2}} \\
& \text { where: } \\
& \mathrm{P}=\text { the ultimate load at fracture, } \\
& \mathrm{l}=\text { the distance of the supports, } \\
& \mathrm{b}=\text { the width of the specimen, } \\
& \mathrm{d}=\text { the thickness of the specimen. }
\end{aligned}
$$

\section{RESISTANCE TO FATIGUE}

The complexity of the oral environment and geometric diversity of cavities filled with restorations make it difficult to precisely define clinical failure processes and to associate routinely measured mechanical properties with dental materials performance. The behavior of these materials under the action of stresses, which are relatively low but intermittent, shows the resistance to fatigue ${ }^{8}$. This method permits measurement of a fatigue limit, with no fracture, at a given number of stress cycles. Compressive fatigue curves are generated when different materials are submitted to cyclic compressive stress. Tests are made with the test machine operation in a given loading frequency.

The presence of defects in the microstructure of the restoration or specimen submitted to high or low stresses leads to the development of cracks. As clinical environment influences are critical factors due to the relatively low stress, these cracks will turn into fracture of the material.

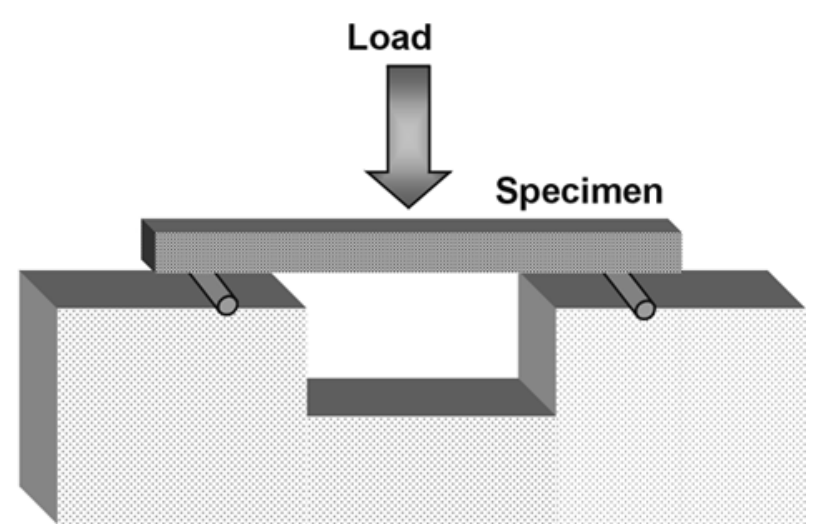

FIGURE 5- Schematic illustration of flexural strength test of a material 


\section{HARDNESS TEST}

Major laboratory tests are performed to investigate products based on their bulk features. However, surface characteristics are also a determinant factor when the material is in service in oral environment. Surfaces characteristics can influence on polishing ability, on the scratching occurrence and on the resistance to load application. Then, surface hardness is a parameter frequently used to evaluate material surface resistance to plastic deformation by penetration ${ }^{3,4,8,17}$. Hardness is not an intrinsic material property dictated by precise definitions in terms of fundamental units of mass, length and time. A hardness property value is the result of a defined measurement procedure.

The usual method to achieve hardness value is to measure the depth or area of an indentation left by an indenter of a specific shape with a specific force applied for a specific time. There are four common standard test methods for expressing the hardness of a material: Brinell, Rockwell, Vickers, and Knoop. Each of these methods is divided into a range of scales, defined by a combination of applied load and indenter geometry.

The Brinell hardness test method consists of indenting the material with a $10 \mathrm{~mm}$ diameter hardened steel or carbide ball subjected to a load. It is the oldest method to measure surface hardness and is applicable to test metal and alloys. The Rockwell hardness test method consists of indenting the test material with a diamond cone or hardened steel ball indenter. This method is useful to evaluate surface hardness of plastic materials used in Dentistry.

The Vickers hardness test method consists of indenting the test material with a diamond indenter, in the form of a right pyramid with a square base and an angle of 136 degrees between opposite faces subjected to a load of 1 to $100 \mathrm{Kgf}$. The load is normally applied for 10 to 15 seconds. The two diagonals of the indentation left in the surface of the material after removal of the load are measured using a microscope and their average calculated. The area of the sloping surface of the indentation is calculated. It is suitable to be applied to determine the hardness of small areas and for very hard materials.

Knoop hardness is more sensitive to surface characteristics of the material. The Knoop indenter is a diamond ground to pyramidal form that produces a diamond shaped indentation having approximate ratio between long and short diagonals of 7:1. The depth of indentation is about $1 / 30$ of its length. When measuring the Knoop hardness, only the longest diagonal of the indentation is measured and this is used in the following formula with the load used to calculate KHN:
$\frac{\mathrm{KHN}=\mathrm{L}}{\mathrm{I}^{2} \mathrm{C}_{\mathrm{p}}}$

where,

$\mathrm{L}=$ load applied,

I= the length of the long diagonal of the indentation,

$\mathrm{C}_{\mathrm{p}}=$ constant relating $\mathrm{l}$ to projected area of the indentation.

Knoop hardness test is applied to evaluate enamel and dentine structures. One of the major difficulties is the requirement of a high polished flat surface that is more time-consuming and more care taking compared to other tests.

Comparing the indentations made with Knoop and Vickers Diamond Pyramid indenters for a given load and test material, there are some technical differences as follow $^{14}$ :

- Vickers indenter penetrates about twice as deep as Knoop indenter

- Vickers indentation diagonal about $1 / 3$ of the length of Knoop major diagonal

- Vickers test is less sensitive to surface conditions than Knoop test

- Vickers test is more sensitive to measurement errors than knoop test

- Vickers test best for small rounded areas

- Knoop test best for small elongated areas

- Knoop test good for very hard brittle materials and very thin sections.

Hardness tests are extremely used and have important applicability on Dentistry. Hardness test can evaluate the degree of mineralization of a dental substrate ${ }^{15,16}$ for example. A specific force applied for a specific time and distance provides important data in studies assessing the ability of enamel and dentin remineralization after different treatments as happens in unbalanced situations of des-remineralization. Another important use of this test is to evaluate the degree of polymerization of resin composite and resin cements. Hardening and depth of cure of these materials can be obtained using Vickers and Knoop micro-hardness test.

\section{CONCLUSIONS}

Since there are many products on the market, it becomes a difficult task to dentists to select dental materials.

Even thought mechanical tests have not reached the level of clinical simulation, they represent an important parameter of analyses. The knowledge of the principal laboratory tests is of high importance. There are many mechanical tests to evaluate dental materials, each of them 
with their characteristics and parameters. This subject is interesting for researchers seeking for the comprehension of the large variety of the available tests. In this manner, this article is of paramount importance since it informs and comments on the variety of scientific approach to evaluate mechanical properties of dental materials.

\section{RESUMO}

Uma grande variedade de produtos odontológicos que são lançados no mercado faz da seleção do material uma difícil tarefa. Apesar das propriedades mecânicas não representarem necessariamente o seu real desempenho clínico, os testes são utilizados para orientar os efeitos das alterações das composições do material ou a evolução das suas propriedades. Além disso, estas propriedades podem ajudar o clínico de alguma forma na seleção correta, uma vez que a comparação entre as formulações anteriores e as mais recentes, assim como as líderes de mercado são mais destacadas pelos fabricantes. Este artigo apresenta uma revisão dos testes laboratoriais mais importantes. Desta forma, o conhecimento destes ensaios fornecerá uma opinião crítica relacionada às propriedades dos diferentes materiais dentários.

UNITERMOS: Materiais dentários, propriedades; Teste de materiais.

\section{REFERENCES}

1-Albers HF. Tooth-colored restoratives. 8.ed. Santa Rosa: Alto Books; 1996.

2-Anusavice KJ. Recent developments in restorative dental ceramics. J Am Dent Ass 1993; 24: 73-84.

3-Anusavice KJ. Propriedades mecânicas dos materiais dentários. In:_ Phillips materiais dentários. 10. ed. Rio de Janeiro: Guanabara Koogan; 1983. p.28-43.

4-Darvell BW. Mechanical testing. In: Materials science for Denstistry. $6^{\text {th }}$ ed. Hong Kong:University of Hong Kong; 2000. p. $1-34$.

5-Carvalho RM, Sano H, Ciuchchi B, Yoshiama M, Pashley DH. Determinação da resistência adesiva a dentina através de um dispositivo de micro-tração. Rev Fac Odontol.Bauru 1994; 22: 77 82 .

6-Cefaly DFG. Resistência à tração diametral e sorção de água de cimentos de ionômero de vidro utilizados no ART. Bauru; 2001. [Dissertação de Mestrado - Faculdade de Odontologia de Bauru, Universidade de São Paulo].
7-Cattani-Lorente MA. Comparative study of the physical properties of a polyacid-modified composite resin and a resin-modified glass ionomer cement. Dent Mater 1999; 15: 21-32.

8-Craig RG. Mechanical properties. In: Restorative dental materials. 10.ed. St. Louis: Mosby, c1997. p. 56-103.

9-Craig RG. Optical, thermal, and electrical properties. In: Restorative dental materials. 10.ed. St. Louis: Mosby, c1997. p.30-55.

10-Garcia FCP, D’Alpino PHP, Terada RSS, Carvalho RM. Testes mecânicos para a avaliação laboratorial da união resina/ dentina. Rev Fac Odontol Bauru 2002; 10: 118-27.

11- International Organization for Standardization. Technical report ISO 9917 Dental water-based cements, Switzerland, 1993.

12- International Organization for standardization. Technical report ISO 9917-2 Dental water-based cements- Part 2: Light-activated cements, Switzerland, 1998.

13-Kemp-Scholte CM, Davidson CL. Marginal sealing of curing contraction gaps in class $\mathrm{V}$ composite resin restorations. J Dent Res 1998; 67: 841-5.

14-Microhardness test. Disponível no http:// www.gordonengland.co.uk/hardness/microhardness.htm). 12 fev. 2003.

15-Pereira PNP, Inokoshi S, Yamada T, Tagami J. Microhardness of in vitro caries inhibition zone adjacent to conventional and resinmodified glass ionomer cements. Dent Mater 1998; 14:179-85.

16- Shinkai RS, Cury AADB, Cury JA. In vitro evaluation of secondary caries development in enamel and root dentin around luted metallic restoration. Oper Dent 2001; 26:52-9.

17-Vieira DF. Propriedades mecânicas. In:__ . Propriedades dos materiais odontológicos. São Paulo: Universidade de São Paulo, 1965. p. 31-89.

18-Vieira DF. Propriedades ou constantes físicas. In: Propriedades dos materiais odontológicos. São Paulo: Universidade de São Paulo, 1965. p. 92- 105.

19-Vieira LCC, Ishikiriama A, Franco EB, Poletto LTA. Reparos em porcelana. Rev Odontol Univ São Paulo 1991; 5: 55-8.

20-Wilson NHF. The evaluation of materials: relationships between laboratory investigations and clinical studies. Oper Dent 1990; 15: 149-55.

Recebido para publicação em: 13/02/2003

Aceito após reformulações em: 06/05/2003

Correspondence to:

Prof. Dr. José Carlos Pereira

Faculdade de Odontologia de Bauru

Departamento de Dentística

Al. Octávio Pinheiro Brisolla, 9-75

17012-901 Bauru, SP - Brasil 